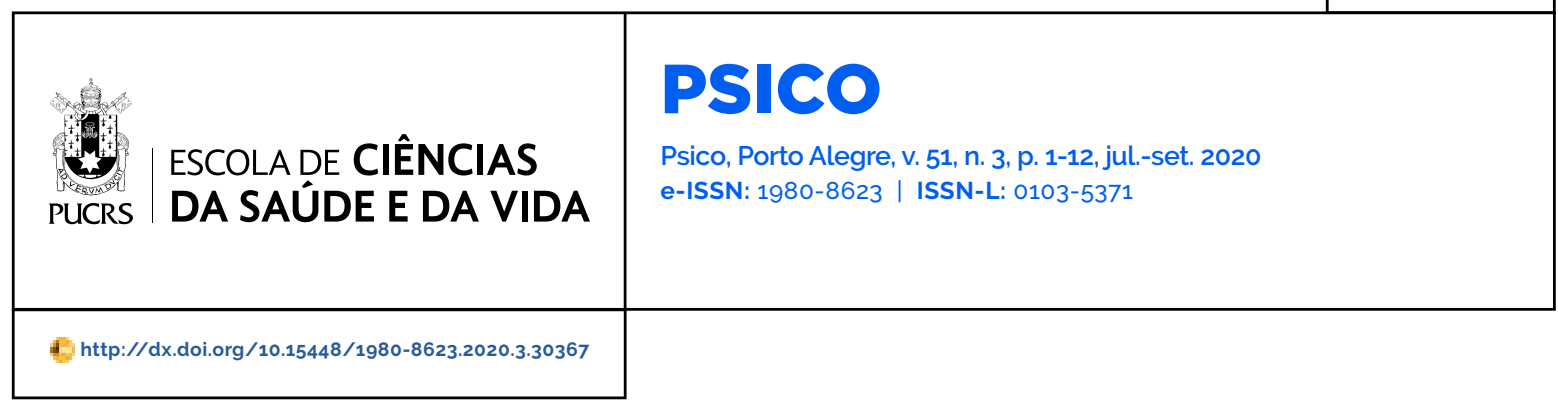

ARTIGOS

\title{
Jogos e intervenções grupais no atendimento de crianças com dificuldades escolares
}

\author{
Games and group interventions to attend children with school difficulties \\ Juegos e intervenciones grupales para atender niños con dificultades escolares
}

Mariana Inés Garbarino ${ }^{1}$ orcid.org/0000-0003-3013-909X marianaigarbarino@gmail.com

\section{Maria Thereza Costa Coelho de Souza ${ }^{1}$} orcid.org/0000-0002-9802-0864 mtdesouza@usp.br

\section{Ana Lúcia Petty ${ }^{1}$}

orcid.org/0000-0002-1037-6728 anapetty44@gmail.com

\section{Camila Tarif Folquitto ${ }^{1}$}

orcid.org/0000-0003-0726-4247 ctariffolquitto@gmail.com

Recebido em: 16/4/2018. Aprovado em: $27 / 2 / 2020$ Publicado em: 21/01/2021.
Resumo: O artigo discute a relevância da utilização de jogos no contexto do atendimento de crianças com dificuldades escolares. Estuda seu potencial como instrumento de observação e de intervenção sustentando-se em duas frentes de análise. Por um lado, examina as contribuições dos jogos de mesa à luz de pesquisas francesas neopiagetianas acerca dos impactos das novas tecnologias no desenvolvimento infantil. Por outro, articula essas discussões com dados oriundos de um Programa de Extensão Universitário destinado a crianças de 7 a 11 anos O método contemplou a sistematização de 172 protocolos correspondentes a 35 participantes. Os resultados destacam as potencialidades do jogo como instrumento de intervenção, e constatam que o interesse e a persistência, por si sós, não garantem procedimentos satisfatórios na resolução de desafios cognitivos e socioafetivos, ao contrário do que afirma o discurso dos adultos, o qual insiste na falta de esforço e de atenção como causas para as dificuldades escolares. Palavras-chave: jogos, fracasso escolar, intervenção psicológica

Abstract: This paper discusses the relevance of using games to attend children with school difficulties. It studies its potential as an instrument of observation and intervention based on two fronts of analysis. On one hand, it examines the contributions of board games from the French neopiagetian research's view about the impact of new technologies on child development. On the other hand it articulates these discussions with data from a University Extension Program for children aged 7 to 11 years. The method involved the systematization of 172 protocols corresponding to 35 participants. The results highlight the potentialities of games as an intervention tool, and note that interest and persistence alone do not guarantee satisfactory procedures in the resolution of cognitive and socio-affective challenges, contrary to adult's arguments that insist on lack of effort and attention as causes for school difficulties.

Keywords: games, school failure, psychological intervention

Resumen: El artículo discute la relevancia de la utilización de juegos en el contexto de atención de niños con dificultades escolares. Estudia su potencial como instrumento de observación e intervención, sustentándose en dos frentes de análisis. Por un lado, examina las contribuciones de los juegos de mesa a la luz de investigaciones francesas neopiagetianas acerca de los impactos de las nuevas tecnologias en el desarrollo infantil. Por otro, articula esas discusiones con datos oriundos de un programa de extensión universitario destinado a niños de 7 a 11 años. El método contempló la sistematización de 172 protocolos correspondientes a 35 participantes. Los resultados destacan las potencialidades del juego como instrumento de intervención y constatan que sólo el interés y la persistencia no garantizan procedimientos satisfactorios para la resolución de desafios cognitivos y socio-afectivos, al contrario de lo que afirma el discurso de los adultos, que insiste en la falta de esfuerzo y atención como causas para las dificultades escolares.

Palabras clave: juegos, fracaso escolar, intervención psicológica 
Os jogos de regras acompanham a filogênese humana há, pelo menos, 5 mil anos, sendo tão antigos quanto a escrita. Desde os antigos egípcios, passando pelos gregos e artistas da idade média europeia e de outros continentes, foram utilizados em metáforas e imagens que nos aproximam ao que não pode ser dito (Lhôte. 2010). Presentes na mitologia e na arte, tanto do Oriente quanto do Ocidente, os jogos foram e continuam sendo o produto de um homo-ludens "improdutivo" (Huizinga, 1996; Caillois, 1986).

Ao longo da história os jogos fizeram parte da cultura apresentando mudanças, tanto de forma como de conteúdo, que possibilitaram diversos usos para além dos relacionados as suas origens. Atualmente, eles se apresentam, inclusive, como instrumentos clínicos no planejamento de intervenções. Nesse campo, os jogos são investigados desde diversas perspectivas teóricas, tais como a piagetiana (Brenelli, 2005: Macedo, Petty \& Passos, 2000, 2005: Missawa \& Rossetti, 2008; Dell'Agli \& Brenelli, 2009, 2010; Santos \& Ortega, 2012; Souza et al., 2014); a cognitiva-comportamental (Taquet, 2015: Doyen et al., 2015: Ramos et al. 2017) e a psicanalítica (Oder, 2008; Levin, 2012; Le Corre, 2015; Garbarino, 2017). As pesquisas de embasamento piagetiano prevalecem nos estudos sobre jogos de regras em comparação, por exemplo, com sua baixa presença na produção psicanalítica. Macedo (2009), precursor do tema no Brasil, define o jogo como um sistema espaço-temporal composto de objetos, objetivos e regras que resulta "funcionalmente ativado pelas ações dos jogadores, nos limites do que se define como partida, torneio ou situação-problema relativa a um recorte ou episódio do jogo" (p. 45).

A psicologia genética (Inhelder \& Cellérier, 1996), já evidenciou que o contexto lúdico permite analisar niveis de desenvolvimento cognitivo e socioafetivo considerando a criança na confluência do sujeito epistêmico (estruturas intuitivas e operatórias) e do sujeito psicológico (qualidade dos procedimentos). O jogo demanda, simultaneamente, operações lógico-matemáticas e aspectos afetivos que impulsionem seu funcionamento. Desse modo, se for mediado por um adulto que ajude a compreender, explicitar ou corrigir procedimentos, o jogo permite estudar modalidades de pensamento, de afetividade e de relações sociais, tornando-se instrumento para avaliar e afiançar atitudes positivas para a resolução de conflitos (Souza, 2005).

Há estudos que vêm sondando as possibilidades de análise empírica e teórica no contexto de intervenções com jogos específicos. A partir do Quips, ${ }^{1}$ Brenelli (2005) abordou noções como equivalência, inclusão, correspondência, seriação e conservação de quantidades. No caso das intervenções com o Ta-te-ti, foram demostradas suas contribuições para a criança aprender a se organizar melhor, lidar com limites e respeitar o outro (Macedo, Petty \& Passos, 2005). O estudo do Tangram evidenciou as relações operatórias que é preciso estabelecer entre as peças, sendo a paciência uma atitude necessária para agir e encontrar soluções dominando gradualmente sua geometria (Macedo, Petty \& Passos, 2005). Já Santos e Ortega (2012) investigaram o desempenho de idosas com o jogo Cara a cara e destacaram que as relações entre regulações afetivas e cognitivas são diversas em cada sujeito, não sendo possivel indicar uma relação padronizada.

O estudo dos efeitos de intervenções com jogos para crianças com suspeita de Transtorno de déficit de atenção e hiperatividade (TDAH) comprovou melhorias nos seus procedimentos, salientando a importância das terapias não medicamentosas que considerem aspectos estruturais do desenvolvimento infantil, para além dos corretivos ou do treinamento que visam acalmar as crianças ou deixá-las mais quietas (Folquitto, 2013). Nessa linha, ojogo Mancala também foi utilizado como instrumento para estudar as condutas de crianças com e sem dificuldades de atenção (Missawa \& Rossetti, 2008).

Embora os jogos tradicionais continuem presentes no universo lúdico infantil, eles constituem uma alternativa clínica de avaliação

\footnotetext{
Jogo lógico-matemático de tabuleiro, com dados e cilindros de colores.
} 
e intervenção que ainda requer pesquisa teórica e empírica. Sendo assim, emerge a seguinte questão: diante do atual panorama de crianças e adolescentes "nativos digitais", quais seriam os impactos e as potencialidades dos jogos de mesa como instrumento para o atendimento das dificuldades escolares?

\section{Do tabuleiro ao tablet: tempo e atenção}

Diversas pesquisas indicam que os jogos eletrônicos ${ }^{2}$ e as telas já fazem parte do cotidiano da população e tentam vislumbrar seus efeitos, inclusive em termos de potencial aditivo (Suzuki et al., 2009; Homer et al., 2012; López-Fernández, Honrubia-Serrano, \& FreixaBlanxart, 2012; Le Heuzey \& Mouren, 2012; Bach et al., 2013). Esse dado não é alheio ao universo da criança escolar (Levin, 2012; Ramos et al., 2017: Garbarino, 2017). Vários estudos já mostram correlações entre horas de uso de videogames na infância e o diagnóstico de TDAH, sentimentos de depressão e/ou de solidão (Taquet, 2015). Ora, se os videogames resultam tão significativos no cotidiano da população infantil, por que utilizar jogos de mesa tradicionais para crianças com dificuldade escolar? Sem negar a importância das contribuições das novas tecnologias no desenvolvimento infantil, é possivel destacar que "do tabuleiro ao tablet" há uma questão temporal que pode ser aproveitada para redimensionar duas das queixas mais frequentes no contexto escolar: os supostos déficit de atenção e a falta de interesse dos alunos. Brevemente, é possivel explorar três dimensões gerais dos indícios de um vínculo em processo de transição entre tempo e jogos no contexto eletrônico e não eletrônico.

Em primeiro lugar, o tempo na dimensão da velocidade se manifesta visivelmente aumentado na ativação dos circuitos cerebrais de recompensas em uma partida de videogame (Houdé, 2015). Isso posto, os jogos trazem desafios psíquicos para a criança, tanto no campo afetivo como cognitivo, em função de apresentarem

\footnotetext{
2 Com o termo "jogos eletrônicos" contemplamos videogames e jogos de internet, em plataformas como consoles, computadores e celulares.
}

coordenadas diferentes da velocidade com que esses circuitos de prazer são dinamizados. Nesse sentido, o aspecto temporal de velocidade permite situar os jogos de mesa em uma dinâmica mais próxima da maior parte das atuais propostas escolares (ainda que já haja sistemas de ensino nos quais prima a mediação com telas). Em segundo lugar, assinalamos a perspectiva do tempo como excesso, em relação às horas de exposição aos videogames e os riscos de adição (Suzuki et al., 2009; Taquet, 2015; Bach et al., 2013). Esse possivel excesso também se relaciona com a mudança da noção de "partida" que já não se circunscreve ao espaço de minutos ou horas de um dia, mas perdura "online", em um contínuo paralelo com a vida não virtual do sujeito. Em terceiro lugar, os videogames nos acompanham em uma escala humana de tempo bem menor do que os jogos de tabuleiro. Ainda que seja uma temática crescentemente estudada, constitui um campo de pesquisas recente com muitas perguntas sem responder acerca dos seus efeitos no desenvolvimento infantil (Cotonhoto \& Rossetti, 2016).

Além dessa questão temporal, outro ponto de interesse da utilização dos jogos é vinculado à massificação de um suposto problema atencional infantil, especialmente difundido a partir do diagnóstico de TDAH, que resulta frequente nos discursos de pais e professores (Bonadio \& Mori, 2013). A atual queixa escolar recorre no apontamento de falta de atenção, concentração, motivação e/ou interesse por parte das crianças (Proença, 2002; Leavy, 2013: Dazzani et al. 2014). Diante desse cenário pode-se observar certo paradoxo no fato de que crianças que apresentam dificuldade em prestar atenção e se concentrar na escola podem, no entanto, ficar absorvidas diante das telas por longos períodos de tempo.

A ponte entre atenção e novas tecnologias foi colocada em uma perspectiva neopiagetiana por Olivier Houdé $(2007,2011,2014,2015)$ e sua equipe do laboratório LaPsyDÉ/Sorbonne. ${ }^{3}$ A partir de

\footnotetext{
3 Laboratoire de Psychologie du Développement et de l'Éducation de l'enfant (Laboratório de Psicologia do Desenvolvimento e da Educação da criança).
} 
técnicas de tomografias computadorizadas eles concluíram que o contato com as telas está trazendo mudanças nas conexões neuronais. 0 sistema de recompensas dos jogos eletrônicos traria uma nova forma de lidar com o prazer lúdico e outras atividades gratificantes (como o uso de redes sociais) que estimulam circuitos de recompensas mais imediatas na liberação de dopamina (Houdé, 2007, 2015).

Diante desse panorama, o termo "geração Z" nomeou os jovens de 12 a 24 anos que cresceram com telefones celulares e videogames. Essa geração teria ganhado em mecanismos cerebrais velozes e automatismos, mas teria perdido em raciocínio e controle de si mesmo (Houdé, 2015). Aliás, o cérebro permanece o mesmo, mas os circuitos funcionais mudaram. Em outras palavras, a geração $Z$ ganhou em velocidade, em detrimento da inibição de condutas impulsivas e intuitivas que é função do córtex pré-frontal. Considerando essa perspectiva, postulou-se que no ato de pensar acontece uma competição entre estratégias cognitivas, explicada a partir de um modelo de organização cerebral configurado em três sistemas (Houdé, 2014)

O Sistema 1 (S1) é intuitivo, perceptivo, automático e ilógico. Nele as estratégias visuais e espaciais dominam. Os jogos eletrônicos ativam, frequentemente, circuitos de prazer, rápidos e curtos, próprios do sistema S1. Já o Sistema 2 é o racional e lógico, enquanto o Sistema 3 é de arbitragem e se ativa para inibir o S1. Em suma, a criança que não exerce o controle inibitório, não bloquearia a estratégia impulsiva do S1, o que põe obstáculos à resolução de tarefas cognitivas posto que é a inibição ou resistência cognitiva a que possibilita o ato de pensar (Houdé, 2007, 2014).

Se, como afirma Houdé, pensar exige negar o automatismo da intuição e do perceptivo, pode-se inferir então que o pensamento reflexivo requer a capacidade de duvidar. E duvidar, por sua vez, consiste em negar a percepção instantânea da nuvem de informação que se apresenta aos sentidos (observáveis) competindo com a tarefa atual e que demanda fazer um recorte, ou seja, uma escolha. A atenção resulta assim em um mecanismo consciente, volitivo e seletivo para coordenar as informações em uma intenção de agir mentalmente. Ela requer uma decisão e um gasto energético para negar (via diferenciação e integração) os estímulos do entorno e ir além do imediato (Houdé, 2007, 2014).

Em vista disso, pode-se concluir que a resistência cognitiva seria o processo que, na linha do desenvolvimento cognitivo postulado pela psicogênese piagetiana (Piaget \& Inhelder, 1966/1972), permite pensar operatoriamente no campo da lógica e da moral. Essas constatações nos levam às seguintes perguntas: a hipótese de Houdé acerca de um enfraquecimento da inibição cognitiva e do aumento de condutas impulsivas é corroborada no contexto de intervenção com jogos de mesa para crianças com dificuldades escolares? É possivel verificar tendências nos procedimentos mais e menos recorrentes que esse instrumento permite observar?

\section{Método}

\section{O dispositivo de intervenção}

A pesquisa foi realizada em um Programa de Intervenção com oficinas de jogos que, desde 1989, funciona como atividade de extensão universitária. Atende crianças de 7 a 11 anos que, majoritariamente, frequentam escolas públicas ou fundações e apresentam queixas escolares (relativas a não aprendizagem de conteúdos, comportamentos inadequados e/ ou atrasos no desenvolvimento). O atendimento é grupal, conformado por 8 a 10 participantes e tem duração de três semestres com encontros semanais de uma hora. As oficinas são organizadas com base em jogos, desafios e situações-problema que exigem diferentes estratégias de resolução além de rodas de conversa sobre temáticas diversas do cotidiano intra e extraescolar. As propostas lúdicas são individuais, em duplas ou grupais e versam sobre jogos de lápis e papel (tais como labirintos, caça-palavras, trava-línguas), jogos de percurso (como Escadas e Serpentes), jogos lógicomatemáticos (tais como Quatro Cores, Dominó 4 cores, Tangram, Sjoelbak, Feche-a-caixa), e 
jogos de comunicação e criação de narrativas (por exemplo, Imagem-ação e Conte um conto).

\section{Participantes}

Os dados coletados na pesquisa corresponderam à análise de protocolos de observação de 35 crianças (15 meninas e 20 meninos) que participaram do programa de intervenção mencionado. Tentou-se aproximar a quantidade de meninos e meninas, mas esta não foi equiparada, fato que deriva da histórica maioria do sexo masculino na procura do atendimento. O perfil da população tinha como denominador comum a queixa escolar, cuja explicação causal, forma e grau de manifestação foi diversificada de acordo com a prevalência de dificuldades de aprendizagem em Lingua Portuguesa e/ou Matemática, queixas por dispersão, falta de interesse, desatenção, problemas de relacionamento e disciplina, e/ou diagnósticos de transtornos específicos e síndromes (suspeita ou diagnóstico de TDAH, dislexia, entre outros). A pesquisa foi submetida e aprovada pelo Comitê de Ética em Pesquisa com Seres Humanos (CEPH) do Instituto de Psicologia da Universidade de São Paulo (IPUSP), conforme parecer $n^{\circ} 1.082 .789$.

\section{Coleta e análise de dados}

Os protocolos de registro analisados $(\mathrm{N}=172)$ correspondem as 35 crianças da amostra e foram produzidos no contexto do atendimento e são referentes a sete semestres, entre 2011 e 2014 O preenchimento aconteceu após cada encontro conforme os procedimentos e as atitudes mais frequentes (um protocolo para cada criança).

O registro teve duas modalidades: o assinalamento de itens predominantes e o comentário narrativo que complementava e justificava a escolha considerando, como indicadores, as ações, as falas, os gestos e a linguagem tônico-muscular das crianças observadas. Os itens do protocolo estavam agrupados em atitudes e procedimentos expansivos e restritivos correspondentes a três momentos da tarefa, tal como mostra a Tabela 1.

Esses protocolos de observação preexistiam à realização da pesquisa e foram elaborados pelos fundadores do atendimento. Em concordância com as duas partes do mencionado protocolo (pontuação de itens e produção escrita narrativa), o método de análise aqui escolhido foi misto. contemplando a descrição quantitativa das recorrências de itens e a análise de conteúdo das observações narrativas registradas pelas pesquisadoras.

Finalmente, cabe justificar a escolha dos termos "expansão" e "restrição" para sistematizar os itens marcados. Essa eleição subsidia-se, por um lado, no modelo psicogenético piagetiano do desenvolvimento na forma de uma espiral

TABELA 1 - Itens expansivos e restritivos do protocolo de observação

\begin{tabular}{lll}
\hline & Itens Expansivos & Itens Restritivos \\
\hline Início da tarefa & planejamento das ações, & impulsividade, \\
& rapidez para começar, & medo/receio, \\
& iniciativa, & demora para começar, \\
& interesse inicial, & passividade, \\
& coragem & desinteresse \\
Realização da tarefa & autonomia, & dependência, \\
& segurança, & insegurança, \\
& análise dos meios, & estratégias aleatórias, \\
& envolvimento, & fuga/dispersão, \\
& interesse geral & desinteresse \\
& persistência, & desistência, \\
& autocontrole, & raiva/desconforto, \\
& enfrentamento do desafio, & não enfrentamento, \\
& uso de diferentes estratégias, compromisso & repetição, \\
& falta de comprometimento
\end{tabular}


integradora que tende à expansão do Eu. Esse postulado conduz o foco da intervenção na construção do si mesmo da criança, em detrimento dos procedimentos escolares de correção. Por outro lado, a seleção desses vocábulos inspirase no referencial teórico de Schlemenson (2009, 2005) que discorre acerca de uma clínica psicopedagógica que visa amplificar e tornar mais complexa a produção simbólica das crianças com dificuldades de aprendizagem, caracterizada pela restrição, rigidez e fragmentação.

A análise quantitativa descritiva dos protocolos visou verificar a recorrência desses itens observados durante o primeiro semestre de participação. O total de 1385 itens marcados foi sistematizado em planilhas de Excel calculando as porcentagens das categorias expansivas e restritivas. $O$ fato de não pretender uma análise estatistica permitiu a escolha dessa ferramenta. A análise qualitativa dos registros das pesquisadoras permitiu contextualizar e ampliar as marcações e os procedimentos singulares de cada participante tomando como referencial metodológico a análise de conteúdo (Castro, Abs, \& Sarriera, 2011).

\section{Resultados e discussão}

A análise do total das marcações realizadas com base na observação de atitudes e procedimentos manifestadas durante o desempenho das crianças na interação com jogos constatou a prevalência de atitudes expansivas, tal como mostra a Tabela 2.

TABELA 2 - Distribuição percentual das atitudes expansivas e restritivas na interação com jogos

\begin{tabular}{lcc}
\hline Atitudes & $N$ & $\%$ \\
\hline Expansivas & 821 & 59 \\
Restritivas & 564 & 41 \\
Total & 1385 & 100 \\
\hline
\end{tabular}

Fonte: Elaborada pelas autoras.

Sendo que a observação de atitudes expansivas superou a das restritivas, e considerando que os protocolos consultados correspondem ao primeiro semestre de atendimento, inicialmente podia-se ter um prognóstico positivo. A partir dessa primeira constatação, no entanto, foi preciso estudar a que faziam referência essas atitudes.

Como consequência dessa indagação foram selecionados dois itens expansivos e dois restritivos para cada um dos três momentos da tarefa, totalizando doze. Os dois restritivos são os que apresentaram maiores porcentagens. No caso dos expansivos, selecionaram-se os extremos, ou seja, os mais e os menos observados. O critério foi escolhido em função de estabelecer quais as áreas preservadas e/ou consolidadas e aquelas que precisavam ser afiançadas e focalizadas durante a intervenção. Cabe salientar que as porcentagens do gráfico não somam 100\% posto que selecionar um item não resultou excludente de marcar outros. A Figura 1 mostra essa sintese da frequência percentual das marcações dos itens.

Figura 1. Distribuição percentual de recorrências

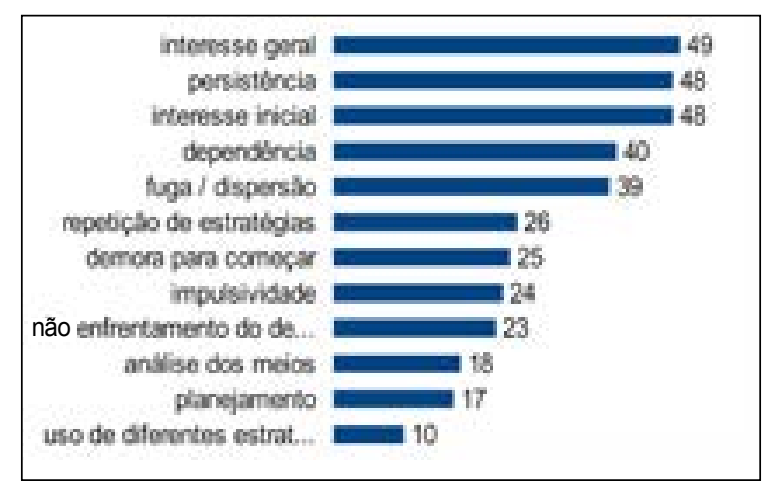

Os itens expansivos mais observados foram interesse inicial (48\%), interesse geral (49\%) e persistência no conflito (48\%). Já o planejamento de ações (17\%), a análise dos meios empregados $(18 \%)$ e o uso de diferentes estratégias (10\%) foram os menos assinalados nos três momentos da atividade: no afrontamento da novidade no início da tarefa, durante sua realização e diante do conflito. No caso dos itens restritivos os mais observados foram: demora para começar (25\%) e impulsividade (24\%) no início da atividade; dependência (40\%) e fuga/dispersão (39\%) no desenrolar da tarefa, e não enfrentamento do desafio (23\%) e repetição de estratégias (26\%) no afrontamento de conflitos. 
Os dados constataram que, mesmo diante da massificação do uso de videogames manifestada pelos pais e crianças participantes das oficinas, os jogos de mesa mantêm sua vigência como ferramenta de intervenção facilitadora da mobilização afetiva para enfrentar a tarefa. Ainda diante da aparente hegemonia da preferência dos videogames é possivel inferir que os jogos com tabuleiros de madeira e lances de dados não teriam "passado de moda" e continuam sendo objeto de interesse entre as crianças escolares. Não obstante isso, e em concordância com as pesquisas de Olivier Houdé (2007, 2011, 2014, 2015) acerca do desenvolvimento infantil na interação com as novas tecnologias, encontramos indicadores que evidenciaram restrições do controle inibitório durante o desenrolar das partidas (impulsividade, pouca análise de meios e planejamento, entre outros). Portanto, caberia concluir que o interesse e a persistência prevalentes nas observações podem ser considerados necessários, mas não suficientes para implementar procedimentos e estratégias de ação no nível operatório do pensamento desejável no contexto de jogos (Dell'Agli \& Brenelli, 2009, 2010).

A predisposição para a tarefa traz a questão de por que crianças interessadas e com disposição no contexto de jogos não apresentam essas atitudes na escola. Formular respostas acabadas seria uma tarefa inócua pela multideterminação do problema escolar e porque contradiria a complexidade da análise interacionista. Além disso, é preciso lembrar que neste trabalho consideraram-se as tendências grupais, o que pode esconder as marcas singulares de cada criança e restringe nossas conclusões nesse nivel. Contudo, cabe sublinhar que os resultados mostraram a prevalência de observações favoráveis nas categorias interesse e persistência, mas, em contrapartida, houve um menor número de indícios de diversificação de estratégias e planejamento, o que indica pouca flexibilidade para procurar outros caminhos de ação e tempo de espera reduzido para pensar antes de agir. Nesse sentido, o nível qualitativo do interesse precisa ser especificado porque pode responder a formas sensoriomotoras ou intuitivo-simbólicas, e não operatórias (Piaget \& Inhelder, 1972; Piaget, 2000).

A sistematização dos dados verificou que aspectos afetivos preservados, como o interesse e a persistência, não são suficientes sem um ajuste dos esquemas que leve a modificações operatórias no agir. A persistência não conduz a equilibrações majorantes (Piaget, 1975/2000) quando só é a expressão de repetição de procedimentos insatisfatórios. Nessa coexistência de persistência e de repetição, identificou-se um desequilibrio entre a assimilação (interesse, mas não operatório) e a acomodação (pouca modificação dos esquemas de ação). Destarte. a criança se manifesta interessada e investe afetivamente no jogo (aspecto energético), mas age de forma errada ou insuficiente em termos de qualidade cognitiva. Quase paradoxalmente. o investimento afetivo que à simples vista parece positivo e "acelerador", põe obstáculos ao pensamento operatório de forma similar ao modelo de Houdé (2014) no qual o sistema intuitivo deve ser inibido para ativar o lógico.

No contexto do atendimento de crianças com dificuldades na escola os jogos extrapolam o estatuto de divertimento, habitual no senso comum, configurando seu valor na tensão cognitiva e afetiva que se manifesta em conflitos, lacunas e erros emergentes nas tentativas de resolução dos desafios. No longo prazo (ao final de três semestres de atendimento), a intervenção promove a amenização do interesse sensório-motor para dar espaço a um interesse operatório. No caso do programa aqui estudado, um mesmo jogo não é apresentado em apenas um encontro, mas em vários (entre cinco e seis). Portanto, o interesse inicial pode se transformar, diminuir ou aumentar. Inicialmente, o jogo resulta um rápido motivador, porém, ao longo da atividade surgem os conflitos, os erros, e a natureza motivadora da tarefa se evidencia transitória. Em concordância com Dell'Agli (2010), em contexto de jogos as crianças com dificuldades de aprendizagem podem manifestar afetos positivos, mas que não necessariamente acompanham mudanças cognitivas.

Além disso, considerar o jogo como provocador 
de desenvolvimento, por si só, implicaria situar-nos em uma posição teórica empirista. Por exemplo, quando o jogo Tangram é apresentado impacta pelo material, pelas cores, pelas formas, enfim, pelo diferencial do jogo como objeto-novidade. Mas após a terceira ou quarta sessão com esse mesmo jogo, o material perde esse atrativo perceptual-motor e o que termina envolvendo o sujeito (ou não) é o desafio de construir formas progressivamente mais complexas. Porque, como aponta Macedo (2009), sem jogadas, o jogo é um mero conjunto de fichas, com formas e cores, que, após o primeiro encontro com seus observáveis mais imediatos, perde seu sentido.

Em suma, explorar os elevados indices desse grande "guarda-chuva" que podemos chamar de "motivação" torna-se relevante para entender porque ela não é suficiente para que seja refletida em um desempenho escolar de melhor qualidade (planejamento e análise dos meios). De acordo com a teoria piagetiana, as observações sistematizadas mostraram que o desempenho operatório dos participantes encontrar-se-ia comprometido pela insuficiência de plasticidade dos esquemas assimiladores para interagir com o conflito, sair da repetição de erros e elaborar novas estratégias. Ou seja, precisam ainda de reversibilidade e de uma equilibração mais estável, e, portanto, mais dinâmica (Piaget, 1975/2000). Esse dinamismo do pensar também é um dos problemas levantados por Schlemenson (2009) e sua equipe, que observam pouca "ductilidade" psíquica nas produções simbólicas de crianças com dificuldades de aprendizagem.

Entretanto, essa plasticidade cognitiva não pode ser dissociada da sua dimensão afetiva. Ao longo dos encontros com os jogos as crianças manifestam distintos sentimentos e emoções como raiva, desconforto, angústia, euforia ou satisfação, tanto em relação às partidas, como aos pares e adultos. A intervenção grupal mobiliza e problematiza posições subjetivas estáticas que costumam ser consolidadas e retroalimentadas no ambiente escolar e familiar. Essas fossilizações não são desconstruidas em pouco tempo, mas precisam de um processo que propicie outros espaços de reconhecimento do si mesmo no discurso social, viabilizando mudar o posicionamento do "não posso", "não consigo" ou das comparações com outras crianças que têm diferentes ritmos de aprendizagem (Proença, 2002: Schlemenson, 2009).

Pesquisas anteriores sobre esse dispositivo já corroboraram que a autorregulação das habilidades sociais (convivência e autoconceito) leva mais tempo, quando comparada com as categorias espaço e objeto (Souza et al., 2014). Uma imagem de si mesmo mais realista (a partir de mecanismos de tomada de consciência das próprias habilidades e limites) corresponde a uma com melhores niveis de autonomia. A relação com o adulto resulta heterônoma (dependência) quando esse é enxergado como um confirmador das ações do qual se depende para dar continuidade à dinâmica do jogo. No caso dos pares, essa dependência se confirma, especialmente, quando as crianças recorrem à imediata e automatizada tentativa de cópia dos procedimentos e resoluções alheios ao invés de tentar resolver os conflitos por si sós (Garbarino, 2017). No contexto das intervenções busca-se estimular que o enfrentamento seja gradualmente feito com mais autonomia e protagonismo.

Finalmente, tendo em vista essas constatações, qual a relevância do uso de jogos no atendimento da queixa escolar? Uma das vantagens já apontadas é a diminuição da tensão que a natureza do jogo propicia (Dell'Agli \& Brenelli, 2009, 2010; Ramos et al., 2017). Ora, a partir dos resultados desse trabalho salientamos o fator da mediação do adulto, sendo que a própria natureza da tarefa, embora a principio resulte atraente pelo seu caráter de novidade, não garante por si só procedimentos de qualidade operatória. Assim, há necessidade de mudanças no papel da intervenção do adulto, mais no sentido da expansão e da diversificação das estratégias de ação do que na insistente demanda verbal de investimento energético (como os recorrentes pedidos de "prestar atenção" ou "se esforçar mais").

Além disso, e tal como apontado por Cotonhoto e Rossetti (2016), embora atualmente os jogos de mesa tradicionais compartilhem o cenário 
lúdico com os videogames, eles não perderam seu atrativo diante das telas. Suas vantagens foram corroboradas nos resultados da pesquisa ao mostrar que atitudes tais como interesse e perseverança prevaleceram nas observações registradas. Simultaneamente, a diminuição da impulsividade (em contrapartida ao planejamento e análise das jogadas) pode ser melhor abordada no contexto das interações sociais e das coordenadas temporais próprias dos jogos de mesa, quando comparadas com o dinamismo dos jogos eletrônicos (Bach et al., 2013). Essas observações vão ao encontro das pesquisas que estudam a elaboração de estratégias de intervenção não medicamentosas diante da crescente presença do diagnóstico de TDAH no contexto escolar (Missawa \& Rossetti, 2008). Os resultados convergem, ademais, com diversos trabalhos que problematizam a ressignificação contemporânea da vivência do tempo para refletir acerca das causas desse transtorno para além das explicações neurobiológicas (Leavy, 2013: Bonadio \& Mori, 2013)

Desse modo, os jogos continuam constituindo ferramentas fecundas para planejar estratégias de intervenção diante das dificuldades de aprendizagem. Nesse campo, várias pesquisas vêm mostrando que os atuais discursos em torno da queixa escolar tendem a resumir e simplificar o problema de aprendizagem em uma questão atitudinal da criança, como sua suposta falta de interesse, motivação e/ou preguiça (Patto, 1997: Proença, 2002; Asbahr \& Lopes, 2006; Paula \& Tfouni, 2009; Ochoa \& Orbeta, 2017). Dentre os efeitos desse reducionismo culpabilizante e individualizante está a medicalização da infância (Leavy, 2013: Guarido, 2007). Os resultados aqui apresentados contradizem essa explicação hegemônica, mostrando que mesmo crianças motivadas e interessadas não são bem-sucedidas sem um adulto que realize uma mediação entre elas e os objetos de conhecimento. Quando isso acontece, a interação com jogos favorece a tomada de consciência dos próprios sentimentos e ações, permitindo identificar as crenças negativas que propiciam a manifestação de posições defensivas favorecedoras de impulsividade (déficit no controle inibitório), rigidez na escolha de estratégias e repetição de erros. Já as crenças positivas promovem melhores niveis de equilibração, que se traduzem em maior flexibilidade cognitiva para a abertura de novas estratégias e para a ampliação de caminhos criativos de resolução.

\section{Considerações finais}

Diante da crescente massificação dos videogames, os jogos de mesa configuram hoje um espaço de resistência cultural e uma alternativa potencial para a diversificação e plasticidade psiquica. Com base nos resultados expostos é possivel afirmar que as intervenções com jogos se orientam no registro da ação, promovendo procedimentos mais eficientes (saber fazer) e preparando o território para a tomada de consciência (compreender). Embora tenha se observado a prevalência do interesse e da perseverança, característicos do espírito lúdico, esses não se mostraram suficientes para um desempenho operatório. A qualidade desse interesse observado correspondeu a um investimento do fazer e representar, próprio de esquemas sensório-motores e/ou simbólicos, mas com pouca postergação do prazer, inibição de impulsos ou mediação da descarga via pensamento operatório.

A construção de estratégias de pensamento bem-sucedidas constitui um processo gradual que requer a mediação do adulto e depende tanto de estruturas cognitivas que permitam a assimilação de um desafio lúdico, quanto de recursos afetivos de qualidade que admitam lidar com o conflito e as incertezas que o jogo propõe. Em outras palavras, a postergação do fazer em prol do pensar precisa tanto da intervenção dos adultos como do confronto com o ponto de vista dos pares, base da construção de mecanismos de autorregulação mais eficientes e plásticos. Assim, além de instrumentalizar a observação do "pensamento em ação", o atendimento grupal com jogos favorece a observação e a análise da interação social, que adquire duas grandes 
vertentes: por um lado, a função que adquire o adulto como mediador e, por outro, as trocas com os pares em dinâmicas grupais ou em duplas que garantem o encontro com a diversidade de pontos de vista, ritmos, habilidades e limites. Desse modo, durante as partidas, o par funciona como suporte, dispersor ou rival, em um ambiente ecológico similar à organização do ambiente escolar.

Desde uma perspectiva intersubjetiva o desenvolvimento psíquico é uma construção entre o Eu e o outro. O sentido de "ser aluno" configura-se em uma construção social e histórica que emerge no encontro com as expectativas dos adultos e das instituições acerca de um determinado comportamento e nível de rendimento acadêmico. Quando o desempenho da criança não resulta como esperado, as explicações causais desse "fracasso" também são uma construção sócio-histórica. As observações realizadas nesta pesquisa podem contribuir para a problematização da queixa escolar ao salientar que a frequente interpretação individualizante e "culpabilizante" da criança acompanhada da mera demanda de esforço por parte dos adultos seria inócua, e até contraproducente, no intuito de favorecer mudanças cognitivas.

Em tempos que apresentam uma forte tendência a intervenções medicamentosas e diagnósticos da neuropsiquiatria, os jogos de mesa se reafirmam como um caminho alternativo para a avaliação e a intervenção no atendimento de crianças com dificuldades escolares. Não obstante, é preciso realizar mais pesquisas que mostrem evidências empíricas dos impactos do uso de jogos para a qualidade de vida infantil no espaço escolar e fora dele, assim como estudos comparativos de desempenho no caso dos jogos eletrônicos e dos tradicionais. Aproveitar e expandir seus beneficios tanto no contexto clínico como escolar, incluindo dispositivos de orientação para familiares e professores, ainda constitui um desafio a ser enfrentado.

\section{Referências}

Asbahr, F. S. F. \& Lopes, J. S. (2006). A culpa é sua. Psicologia USP, 17(1), 53-73. https://doi.org/10.1590/ $\underline{\text { S0103-65642006000100005 }}$
Bach, J., Houdé, O., Léna, P., Tisseron, S. (2013). L'enfant et les écrans. Institut de France, Académie des Sciences.

Bonadio, R. \& Mori, N. N. R. (2013). O TDAH para a comunidade escolar. In Bonadio \& Mori. Transtorno de déficit de atenção/ hiperatividade: diagnóstico da prática pedagógica [online]. Maringá: Eduem, 181-219. https://doi.org/10.7476/9788576286578

Brenelli, R. P. (2005). Uma proposta psicopedagógica com jogos de regras. In F. Sisto (Org.), Atuação psicopedagógica e aprendizagem escolar. Petrópolis: Vozes.

Caillois, R. (1986). Los juegos y los hombres. La máscara y el vértigo. México: FCE,

Castro, T. G., Abs, D., \& Sarriera, J. C. (2011). Análise de conteúdo em pesquisas de Psicologia. Psicologia: Ciência e Profissão, Brasília, 31(4), 814-825. https://doi. org/10.1590/S1414-98932011000400011

Cotonhoto, L. A. \& Rossetti, C. B. (2016). Prática de jogos eletrônicos por crianças pequenas: o que dizem as pesquisas recentes? Rev Psicopedagogia, 33(102), 346-357.

Dell'Agli B. A. \& Brenelli, R. P. (2009). Análise dos aspectos afetivos em atividades lúdicas e escolares. In L. Macedo (Org.), Jogos, psicologia e educação: teoria e pesquisas. São Paulo: Casa do Psicólogo.

Dell'Agli B. A. \& Brenelli, R. P. (2010). Dificuldades de aprendizagem: análise das dimensões afetiva e cognitiva. In L. Caetano, (Org.), Temas atuais para a formação de professores, contribuições da pesquisa piagetiana. São Paulo: Paulinas, 45-70.

Doyen, C., Contejeana, Y., Rislera, V., Aschb, M., Amadoc, I., Launayd, C., De Bois Redona, P., Burnoufa, I., \& Kaye, K. (2015). Thérapie par remédiation cognitive chez les enfants: données de la littérature et application clinique dans un service de psychiatrie de l'enfant et de l'adolescent. Archives de Pédiatrie, 22, 418-426. https://doi.org/10.1016/j.arcped.2015.01.012 PMid:25736104

Folquitto, C.T.F. (2013). Desenvolvimento psicológico e estratégias de intervenção em crianças com Transtorno de Déficit de Atenção e Hiperatividade (TDAH). (Tese de doutorado). Instituto de Psicologia, Universidade de São Paulo, SP.

Garbarino, M. I. (2017). Construção do prazer de pensar e desenvolvimento: um estudo teóricoclinico com crianças em dificuldade escolar. (Tese de doutorado). Instituto de Psicologia, Universidade de São Paulo, SP

Guarido, R. (2007). A medicalização do sofrimento psiquico: considerações sobre o discurso psiquiátrico e seus efeitos na educação, Educação e Pesquisa, 33(1), 151-161. https://doi.org/10.1590/S151797022007000100010

Homer, B. D.; Elizabeth O.; Hayward, Jonathan Frye \& Jan L. Plass (2012). Gender and player characteristics in video game play of preadolescents. Computers in Human Behavior, 28, 1782-1789. https://doi. org/10.1016/i.chb.2012.04.018 
Houdé O. (2007). Le rôle positif de l'inhibition dans le développement cognitif de l'enfant. Le Journal des psychologues, 1(244), 40-42. https://doi.org/10.3917/ jdp.244.0040

Houdé, O. (2011). La psychologie de l'enfant. Coleção Que sais-je? Paris: Puf.

Houdé, O. (2014). Le raisonnement. Coleção Que saisje? Paris: Puf

Houdé, O. (2015). Génération Z: le cerveau des enfants du numérique. Entretien avec Olivier Houdé. Sciences et Avenir, AFP.

Huizinga, J. (1996). Homo ludens: o jogo como elemento da cultura. São Paulo: Perspectiva. (Trabalho original publicado em 1938). https://doi. org/10.1515/9783110810615

Inhelder, B. \& Cellérier, G. (1996). O desenrolar das descobertas da criança: um estudo sobre as microgêneses cognitivas. Porto Alegre: Artes Médicas.

Le Corre, V. (2015). De quelques aspects de l'expérience vidéo-ludique. Savoirs et clinique, 1(18), 43-52. https://doi.org/10.3917/sc.018.0043

Le Heuzey, M. F. \& Mouren, M. C. (2012). Addiction aux jeux vidéo: des enfants à risque ou un risque pour tous les enfants? Bull. Acad. Natle Méd., 196(1), 15-26.

Leavy, P. (2013). ¿Trastorno o mala educación? Reflexiones desde la antropologia de la niñez sobre un caso de TDAH en el ámbito escolar. Rev. Lat. de Ciencias Sociales, Niñez y Juventud, 11(2), 675-688 https://doi.org/10.11600/1692715x.11215101012

Levin, E. (2012). Angustia, diagnósticos e infancia ¿dónde está el sujeto? Prâksis - Rev do ICHLA, Instituto de Ciências Humanas, Letras e Artes, vol. 2 (Jul-Dic)

Lhôte, J. M. (2010). Le symbolisme des jeux. Paris: Éd. Berg International.

López-Fernández, O.; Honrubia-Serrano, M. L. \& Freixa-Blanxart, M. (2012). Adaptación española del "Mobile Phone Problem Use Scale" para población adolescente. Adicciones, [S.L.], v. 24, n. 2, p. 123-130, jun. https://doi.org/10.20882/adicciones.104

Macedo, L. (2009). Jogos, psicologia e educação: teoria e pesquisas. São Paulo: Casa do Psicólogo.

Macedo, L.; Petty, A. L. \& Passos, N. C. (2000). Aprender com jogos e situações-problemas. Porto Alegre: Artmed.

Macedo, L.; Petty, A. L. \& Passos, N. C. (2005). Os jogos e o lúdico na aprendizagem escolar. Porto Alegre: Artmed.

Dazzani, M. V., De Oliveira Cunha, E., Monteiro Luttigards, P., Silva do Vale Zucoloto, P. C., Lima

dos Santos, G. (2014). Queixa escolar: uma revisão crítica da produção científica nacional. Psic Escolar e Educacional, 18. https://doi.org/10.1590/2175$3539 / 2014 / 0183762$
Missawa, D. \& Rossetti, C. B. (2008). Desempenho de crianças com e sem dificuldades de atenção no jogo Mancala. Arquivos Brasileiros de Psicologia, 60(2), $60-74$

Ochoa, M. P. \& Orbeta, C. T. (2017). Discursos sobre clase social y meritocracia de escolares vulnerables en Chile. Cadernos de Pesquisa, 47(164), 496-518. https://doi.org/10.1590/19805314.3752

Oder, A. (2008). The use of board games in child psychotherapy. Journal of Child Psychotherapy. online, Association of Child Psychotherapists.

Patto, M. H. S. (1997). Para uma Crítica da Razão Psicométrica. Psicol. USP, 8(1). https://doi. org/10.1590/S0103-65641997000100004

Paula, F. S. \& Tfouni, L. V. (2009). A persistência do fracasso escolar: desigualdade e ideologia. Rev Bras de Orientação Profissional, 10(2), 117-127.

Piaget, J. (2000). La equilibración de las estruturas cognitivas. Problema central del desarrollo. México Siglo XXI. (Trabalho original publicado em 1975)

Piaget, J. \& Inhelder B. (1972). La Psicología del Niño. Madrid: Ed. Morata. (Trabalho original publicado em 1966).

Proença, M. (2002). Problemas de aprendizagem ou problemas de escolarização? Repensando o cotidiano escolar à luz da perspectiva histórico-critica em psicologia. In M. K. Oliveira, D. T. R. Souza \& M. T. Rego (Orgs.), Psicologia, educação e as temáticas da vida contemporânea (pp. 177-196) São Paulo: Moderna.

Ramos, D. K., Rocha, N. L., Rodrigues, K. J. R., \& Roisenberg, B. B. (2017). O uso de jogos cognitivos no contexto escolar: contribuições às funções executivas. Psicologia Escolar e Educacional, 21(2), 265-275. https://doi.org/10.1590/21753539201702121113

Santos, C. C. \& Ortega, A. C. (2012). Relações entre Aspectos Cognitivos e Afetivos em Idosas. SCHEME, Rev Eletrônica de psic e epistemologia genéticas, 4(1)

Schlemenson, S. (2005). Enfoque psicoanalítico del tratamiento psicopedagógico. Cadernos de Psicopedagogia, 5(9)

Schlemenson, S. (2009). La clínica en el tratamiento psicopedagógico. Buenos Aires: Paidós

Souza, M. T. C. Intervenção psicopedagógica: como e o que planejar? In Fermino F. (Org.), Atuação Psicopedagógica e aprendizagem escolar. Petrópolis, RJ: Vozes, 1996/2005

Souza, M. T. C., Petty, A. L., Folquitto, C. T. F., Garbarino, M. I. \& Monteiro, T. A. (2014). Does playing games contribute to develop better attitudes? Psychology Research, 4(4), 301-309.

Suzuki, F. T. I., Matias, M. V., Silva, M. T. A., \& Oliveira, M. P. M. T. (2009). O uso de videogames, jogos de computador e internet por uma amostra de universitários da Universidade de São Paulo. Jornal Brasileiro de Psiquiatria, 58(3), 162-168. https://doi. org/10.1590/S0047-20852009000300004 
Taquet, P. (2015). Addiction au jeu video: Processus cognitifs, emotionnels et comportementaux impliqués dans son émergence, son maintien et sa prise en charge. (Tese de doutorado. Université Charles de Gaulle - Lille III, Lille).

\section{Endereço para correspondência:}

Mariana Inés Garbarino

Universidade Federal de São Paulo

Estrada do Caminho Velho, 333, sala 124

Jardim Nova Cidade

07252-312 - Guarulhos, SP, Brasil

\section{Mariana Inés Garbarino}

Doutora em Psicologia pela Universidade de São Paulo (USP), em São Paulo, SP, Brasil; professora substituta da Universidade Federal de São Paulo (UNIFESP), em Guarulhos, SP, Brasil.

\section{Maria Thereza Costa Coelho de Souza}

Doutora em Psicologia pela Universidade de São Paulo (USP), em São Paulo, SP, Brasil; professora titular da Universidade de São Paulo (USP), em São Paulo, SP. Brasil.

\section{Ana Lúcia Petty}

Mestre em Psicologia pela Universidade de São Paulo (USP), em São Paulo, SP, Brasil; Técnica da Universidade de São Paulo (USP), em São Paulo, SP, Brasil.

\section{Camila Tarif Folquitto}

Doutora em Psicologia pela Universidade de São Paulo (USP), em São Paulo, SP, Brasil. 